Factor $(a)$ is removed by poisoning the diseased trees with 'Atlas Tree Killer' solution and thus killing them at once; factor (b) by tapping all the apparently healthy trees found in the diseased locality, and girdling and treating with poison all those that afterwards show the disease; and factor $(c)$ is eliminated automatically, or the removal of the factors $(a)$ and $(b)$ naturally converts the viruliferous insects into non-viruliferous ones.

As indicating the rapidity of spread of this disease, in the North Salem Forest Division alone 'spike' first appeared in 1913. Twenty years later the infected area was 54,000 acres and in 1938 approximately 99,500 acres. Figures so far available indicate that the annual amounts spent on this research work have been but a fraction of the annual losses inflicted by the disease and of the sums saved. It is a classic example, as the authors say, "that 'academic' research can often be utilized by a practical forest department at a reasonably low additional expenditure to produce 'practical' results of immediate financial value". For quite contrary reasons the attention of the Governments of Burma and Nigeria may be directed to this valuable paper.

\section{LYMPHATIC SYSTEM OF THE ANURA}

A CONSIDERABLE amount of work on the lymphatic system of the lower vertebrates has been published in recent years. A recent treatise (Amer. Anat. Mem., No. 18; 1939) is a survey of that work as it affects the Anura in particular. It is not simply a review of the literature, although this is fully taken into account and critically examined, but is also a description of the development of the lymph-and their relation to the blood-vessels, based upon hundreds of injections (both single and double) of five species of frogs, five species of urodeles, and two species of fish.

Dr. H. M. Knower, the author, first started investigating this problem in 1903, and in 1908 described a microinjector which has proved of considerable value in this rather difficult subject. The work is illustrated by forty excellent drawings on nineteen plates and five text-figures. The drawings are all of preparations of Rana palustris, save five which are of $R$. catesbiana. It is claimed that the method of injection, if carefully checked, provides a more satisfactory approach than the study of transverse sections of uninjected material, and with this most zoologists who have tried tracing these elusive vessels in sections will agree.

The first lymphatics appear when a complete blood circulatory system has been established, and are accessory or supplemental to the veins. They appear in connexion with the pronephric glands and the adjacent segmental glands, and this dorso-lateral plexus, in which the anterior lymph heart develops, drains into the pronephric sinus by a short vein. From this stage the development of the system is followed until the establishment of the definitive condition of the late tadpole. It is a pity that the zoological practice of putting specific names in italics has not been followed and that on p. 23, for example, $R$. nig. appears presumably for $R$. nigromaculata, and that throughout the name toad is used again presumably for some species of Bufo.

\section{SEVENTY YEARS AGO}

\author{
NATURE, vol. 2, May I2, I870
}

\section{A Building for the Learned Societies}

The Statistical Society has done good service to the cause of science in convening representatives of the learned societies, to consider whether it would not be possible to obtain a building for their accommodation worthy of the high position they occupy in this great metropolis. "Some of the societies have no reason to complain, the Royal Society, the Linnean, the Royal Astronomical, the Geological, the Chemical, the Society of Antiquaries, and a few others, are well accommodated, and a solid structure is being raised for them in Piccadilly."

The article goes on to point out that financial objections might be raised to a scheme for a now home for learned societies. To this the reply is that the Government should provide one or more buildings for the purpose. "Nowhere does the State do so little for science as in this country. The estimates for 1870-71 give the entire sum to be applied to the learned societies at $2,370 l$ - a sum distributed among very few of them. . . . In addition to this $160,000 l$ are appropriated to a building for certain learned societies in Burlington House; but it will serve for very few of them ; and if we are rightly informed, the Government will reoccupy all the buildings in Somerset House now used by learned societies."

In the event that the Government refused to provide funds for a suitable building, the formation is suggested of a joint-stock company, the shares in which would be taken up by the members of the societies interested. "It has been estimated that the probable cost of a building sufficiently commodious, though not ornamental, in some eligible locality near Charing Cross, will be, with the ground-rent, 30,000 $l$. to $40,000 l . "$

\section{Strange Noises heard at Sea off Grey Town}

Mr. Charles Dennehy, of the R.M.S. Shannon, describes a peculiar noise heard on board iron vessels anchored off Grey Town, at the mouth of the River St. Juan, which separates Nicaragua from Costa Rica. Vessels are obliged to anchor in seven to eight fathoms of water outside the bar, and crews are regularly awakened at night by "a peculiar metallic vibratory sound". This noise, which commences "with a marvellous punctuality at about midnight", continues for about two hours with one or two very short intervals. The noise is not heard on shore, or on coppered wooden vessels. The bottom consists of a heavy dark sand and mud containing much vegetable matter brought down by the river. "The ship is undoubtedly one of the principal instruments in its production. She is in fact for the time being converted into a great musical sounding board."

The letter is followed by the brief comment : "Our correspondent should dredge.-Ed."

REFERENCE is made to the fact that a considerable number of papers are on hand at the Royal Society, and only two more meetings have been arranged for the session. Were not the present arrangements of the Royal Society meetings made to meet conditions long since passed away? And since the flow of papers into the Society has largely increased, why should not the outflow be a little accelerated? 